\title{
Adsorption characteristics of WFD heavy metal ions on new biosourced polyimide films determined by electrochemical impedance spectroscopy
}

Ibtissem Jlalia ${ }^{1}$, Fares Zouaoui ${ }^{2}$, Taha Chabbah ${ }^{1,4}$, Saber Chatti ${ }^{1}$, Patrice Saint-Martin ${ }^{2}$, Herve Casabianca ${ }^{2}$, Sylvain Minot ${ }^{2}$, Francois Bessueille ${ }^{2}$, Catherine Marestin ${ }^{3}$, Regis Mercier ${ }^{3}$, Abdelhamid Errachid ${ }^{2}$, Houyem Abderrazak $^{1}$, Mohamed Hammami ${ }^{1}$ and Nicole Jaffrezic-Renault ${ }^{2, *}$

1 National Institute of Research and Physicochemical Analysis (INRAP), Biotechnopole of Sidi Thabet, 2020 Ariana, Tunisia

2 University of Lyon, Institute of Analytical Sciences, UMR 5280, 5 Rue de la Doua, 69100 Villeurbanne, France

3 University of Lyon, Institute of Polymer Materials, UMR 5223, 5 Rue V. Grignard, 69622 Villeurbanne Cedex, France

4 University of Tunis El Manar, Faculty of Sciences, Farhat Hached Universitary campus, 1068 Tunis, Tunisia

* Corresponding author: nicole.jaffrezic@univ-lyon1.fr

\begin{abstract}
:
In this work, innovative biosourced polyimide polymers were derived from novel combinations of monomers (Isosorbide, 6-FDA and amine cardo). These polymers were obtained with satisfactory yields by polycondensation of different percentages of isosorbide and of 6-FDA (from $100 \%$ to $0 \%$ ). The synthesized polyimides had number average molecular weight in the $17600-22000 \mathrm{~g} / \mathrm{mol}$ range, and they were stable well above $451{ }^{\circ} \mathrm{C}\left(5 \%\right.$ weight loss in $\left.\mathrm{N}_{2}\right)$. The glass transition temperature $(\mathrm{Tg})$ were found to be in the range of $318-414{ }^{\circ} \mathrm{C}$, depending on the composition of the copolymers. The adsorption of Water Framework Directive (WFD) heavy metals $\left(\mathrm{Pb}^{2+}, \mathrm{Ni}^{2+}, \mathrm{Cd}^{2+}, \mathrm{Hg}^{2+}\right)$ on the biosourced polyimide films deposited on a gold electrode was monitored by the measurements of the impedance of the electrolyte/polyimide polymer/electrode interface. The adsorption isotherm of $\mathrm{Pb}^{2+}$ on the different polyimide films was modeled according to a Langmuir isotherm with a best fitting. The relative adsorption capacities were higher when the isosorbide content was higher. Comparing the adsorption capacities of the different WFD heavy metals of the isosorbide based polyimide, the sequence is the following one: $\mathrm{Pb}^{2+} \approx \mathrm{Ni}^{2+}>\mathrm{Cd}^{2+}>\mathrm{Hg}^{2+}$. These results are within the paradigm of Pearson's HSAB principle about the metal-oxygen interaction. When isosorbide based polyimide is the sensitive part of an impedimetric sensor, the detection limit for all the WFD
\end{abstract}


heavy metals is $50 \mathrm{pM}$, very lower than the environmental quality standards for these WFD priority hazardous substances.

Keywords: Bio-based polyimide polymers; Heavy metals; Isotherm model; Detection.

\section{Introduction}

Heavy metals for instance cadmium, lead, nickel and mercury, are subject to important health and environmental monitoring ${ }^{1}$. They are emitted mainly from various industrial activities such as metal plating facilities, mining operations, fertilizer industries, tanneries, batteries, paper industries and pesticides, etc ${ }^{2}$. Unlike organic contaminants, heavy metals are not biodegradable and tend to accrue in living organisms ${ }^{3}$. The accumulation of heavy metals can cause eminent health problems, such as serious toxicological concerns, central nervous system damage, impairment of pulmonary and kidney function ${ }^{4}$.

The Water Framework Directive (WFD) that governs European water policy cites four metals: lead, cadmium, nickel and mercury. The WFD has been placed as the main European regulation for the protection of the water resources ${ }^{5}$. One of its principal objectives is to achieve good chemical and ecological status and to restore and to preserve water bodies at a "good status". Chemical status refers to specific pollutants (e.g., priority substances or priority hazardous substances) and environmental quality standards (EQS) are defined for them. Environmental Quality Standards (EQS) for $\mathrm{Cd}, \mathrm{Ni}, \mathrm{Pb}$, and $\mathrm{Hg}$ are, respectively, 0.7-2.2, 341, 35, and 0.25 nM. As the WFD implementation gradually comes into effect in European countries, the environmental metrology and remediation become a big challenge.

Therefore, several laboratories have focused on the conception and development of efficient methods for the removal of these toxic ion pollutants such as ion-exchange ${ }^{6}$, chemical precipitation $^{7}$, adsorption ${ }^{8}$, membrane filtration $^{9}$ and electrochemical treatment technologies ${ }^{10}$. In order to accurately assess contamination levels, a large number of analysis' methods and processes for the determination of trace substances were developed. These techniques are principally classified as optical techniques ${ }^{11}$ and highly sensitive spectroscopic techniques ${ }^{12}$. These later include atomic absorption spectroscopy (AAS) ${ }^{13}$, inductively coupled plasma mass spectroscopy (ICP-MS) ${ }^{14}$,neutron activation analysis (NAA), X-ray fluorescence spectrometry $(\mathrm{XRF})^{15}$, laser induced breakdown spectroscopy (LIBS) ${ }^{16}$, ion chromatography (IC) ${ }^{17}$ and UVVisible spectrometry (UV-VIS) ${ }^{18}$. These analytical techniques must combine selectivity and 
high sensitivity while respecting many imperatives. ${ }^{19}$ However, these spectroscopic techniques are very expensive and complex and are not suitable for field application. Electrochemical sensors ${ }^{20}$ can be considered as the best alternative because of their experimental simplicity, exceptional detectability, well suited for miniaturization and especially for their low cost. In this context, several electrochemical techniques ${ }^{21}$ have been advanced in the field of heavy metals detection such as cyclic voltammetry $(\mathrm{CV})^{22}$, anodic stripping voltammetry $(\mathrm{ASV})^{23}$, square wave anodic stripping voltammetry $(\mathrm{SWASV})^{24}$, electrochemiluminescence $(\mathrm{ECL})^{25}$ or electrochemical impedance spectroscopy $(E I S)^{26}$. Nevertheless, these electrochemical techniques require development in the design to improve their performance in the detection of heavy metal ions, in particular the modification of the electrode ${ }^{27}$ which is a problem linked to its reusability because the reduced deposited metal must be eliminated with aggressive solutions, not compatible with the on field use.

Recently, organic electrode materials have become a wise choice for the manufacture of electrodes because of their structural diversity, high specific capacity, renewability, lower cost and respect for the environment ${ }^{28}$.Various technologies have been presented, using organic polymers such as polyaniline ${ }^{29}$, polypyrrole ${ }^{30}$, polythiophene ${ }^{31}$.In fact, polyimides(PI)are widely used thanks to their excellent overall properties, high thermal stability, suitable Tg, high mechanical resistance, high resistance to radiation and solvents, good optical, properties high breakdown voltage and easy processability as coatings or film ${ }^{32}$.As a consequence, they can find a wide range of various sensor applications ${ }^{33}$ :as the sensitive part for humidity sensors ${ }^{34}$, as the substrate for $\mathrm{pH}$ sensors ${ }^{35}$, as porphyrinated sensitive fluorescent part for hydrogen chloride gas sensors ${ }^{36}$, as sensitive part for salinity sensors ${ }^{37}$, as porphyrinated sensitive fluorescent part for trinitrophenol sensors ${ }^{38}$ and as sensitive part for dopamine electrochemical sensors $^{39}$. Several types of polyimide polymers were identified for adsorption phases of heavy metal ions: poly(hydriazide-imide) $\mathrm{s}^{40}$, poly(amide-hydrazide-imide) $\mathrm{s}^{41}$ and xanthone-based polyimides ${ }^{42}$. In this context, successful interactions between PI and metals ions are essential in the applications of sorbents and sensors. It is worth to note that the properties of PIare considerably affected by their source materials, including the types of diamines and dianhydrides, imidization processes and drying methods.

The challenge in this work consists on the synthesis and characterization of new partially biosoursed polyimides derived from novel combinations of monomers (Isosorbide, 6-FDA and amine cardo), which can participate in the development of polyimides modified gold electrodes for the impedimetric detection of $\mathrm{Cd}, \mathrm{Ni}, \mathrm{Pb}$ and $\mathrm{Hg}$. Copolymerization of the chosen 
homopolyimides may result in the combination of the base properties of each homopolymer which can lead to improved separation performance of the resulting co-polymer. The incorporation of isosorbide into polymer can generate superior rigidity, high thermal property, biodegradability, attractive hydrophilicity and wettability, as well as non-toxicity ${ }^{43}$. On the other hand, the presence of $\mathrm{CF}_{3}$ in the 6FDA structure has a hydrophobic property in contrast to biosourced isosorbide and improves, in addition, the rigidity of the chain ${ }^{44}$.In our study the amine cardo was introduced in all the elaborated polymers in order to improve thereby processability and solubility ${ }^{45-46}$.

The main aim of this study is to design new partially biosoursed polyimides and copolyimides for the modification of gold electrodes. Each synthesized polymer was fully characterized using NMR spectroscopy, GPC, TMA and TGA. After the structural characterization and the thermal analysis, the adsorption properties of the polyimide modified electrodes were then monitored with electrochemical impedance spectroscopy ${ }^{47}$.

\section{Materials and Methods}

\subsection{Reagents and Standards}

Isosorbide (98\%, recrystallized from acetone), Sodium hydride (60\% dispersion in mineral oil), 4-nitrophthalonitrile (99\%), 2,2'-bis-(3,4'-dicarboxyphenyl) hexafluoropropanedianhydride (6FDA or (6)) (>99.0\%),4,4'-(9-Fluorenylidene) dianiline (CARDO or (7)) (99\%) were purchased from Sigma-Aldrich. M-cresol (99\%) were purchased from Acros Organics and all the other solvents were of analytical grade and used as received.

Solutions of metallic ions were prepared from standard solutions for AAS in nitric acid (SigmaAldrich). Potassium citrate tribasic monohydrate (98\%) and ethylenediamine tetraacetic acid (EDTA, 99\%) were purchased from Sigma-Aldrich.

\subsection{Monomer Synthesis}

The synthesis of dianhydride derived from isohexide was optimized according to a literature procedure $^{44}$ that comprised three steps as described in Figure 1. 
<smiles>OC1COC2C1OC[C@@H]2O</smiles>

(1)<smiles>N#Cc1ccc([N+](=O)[O-])cc1C#N</smiles>

(2)

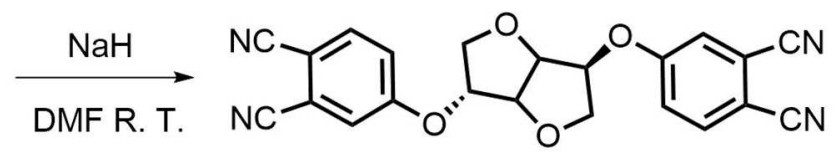

(3)

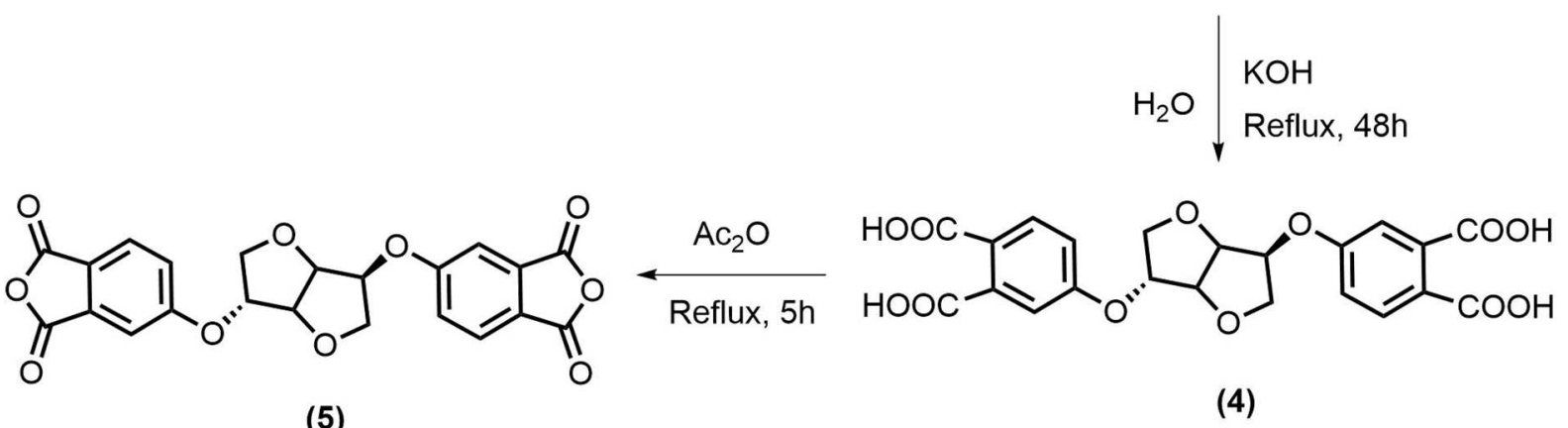

(5)

(4)

Figure 1: Preparative route for isohexide-derived dianhydrides (5)

\subsubsection{Synthesis 1,4:3,6-dianhydro-2,5-bis-(3-4-dinitrile-phenyl)-D-sorbitol (3)}

Isosorbide (1)(4.39 g; $30 \mathrm{mmol})$ and DMF (60 mL) were taken in a $150 \mathrm{~mL}$ three necked flask, which was equipped with a magnetic stirrer and a nitrogen inlet and outlet. The mixture was stirred at $0^{\circ} \mathrm{C}$ for $15 \mathrm{~min}$, Sodium hydride $(2.65 \mathrm{~g} ; 65 \mathrm{mmol})$ was added to the mixture. After stirring for 1h, 4-nitrophthalonitrile (2)(11.25g; $65 \mathrm{mmol})$ was introduced in small portions. The solution was stirred for $24 \mathrm{~h}$ at room temperature and then the reaction mixture was poured in $100 \mathrm{~mL}$ of water. The aqueous layer was extracted three times with ethyl acetate, the organic fractions were combined, and dried over magnesium sulfate. The solvent was removed by rotary evaporation, and the solid was dried at $100^{\circ} \mathrm{C}$ under vacuum to afford (?). A yellowish powder was obtained. Yield : (11.95 g; 99\%).

2.2.2 Synthesis of 2,5-bis(3,4-dicarboxyphenoxy)-1,4:3,6- dianhydrosorbitol (4)

The intermediate (3) (30 mmol, $11.95 \mathrm{~g})$ was suspended in water $(330 \mathrm{~mL})$ with $\mathrm{KOH}$ (11 eq, $372 \mathrm{mmol}, 12.45 \mathrm{~g}$ ) in a two necked round bottom flask and stirred magnetically. The medium was warmed to $100{ }^{\circ} \mathrm{C}$ and the reaction was refluxed for $48 \mathrm{~h}$. After completion (TLC control), the mixture was cooled to room temperature and a few drops of $\mathrm{HCl}$ (cc) were added up to precipitate formation. The addition was continued until acidic $\mathrm{pH}$ was reached $(\mathrm{pH}=2-$ 3). The aqueous layer was extracted three times with ethyl acetate, the organic fractions were combined, washed with water, and dried over magnesium sulfate. The solvent was removed by rotary evaporation, and the solid was dried under vacuum to afford. The acid was recovered as a yellow solid. Yield : (93\%).

2.2.3. Synthesis of 1,4:3,6- dianhydro-2,5-bis(3,4-dicarboxyphenoxy)- D-Sorbitol)(5) 
The monomer (5)was prepared by refluxing $10 \mathrm{mmol}$ of tetra-acid in an acetic anhydride $(25 \mathrm{~mL})$ for $4 \mathrm{~h}$ at $120^{\circ} \mathrm{C}$. Upon cooling, the residue was precipitated in diethyl ether $(100 \mathrm{~mL})$, was filtered and washed to obtain a beige powder. Yield: (92\%).

\subsection{Synthesis of polymers and copolymers}

In this work, all polyimides were prepared via a conventional one-step method in mcresol. A representative procedure follows. An equimolar amount of dianhydride and diamine monomers were used and m-cresol (cc 20\%) was charged into a three-necked, round-bottomed, $25 \mathrm{~mL}$ flask equipped with a mechanical stirrer, and gas inlet and outlet. The reaction mixture was heated for $3 \mathrm{~h}$ at $180^{\circ} \mathrm{C}$ under a mild nitrogen flow. After polymerization, the reaction mixture was cooled to room temperature, and precipitated into methanol. The fibrous precipitate was collected by filtration, washed with methanol, Soxhlet extracted with methanol for $24 \mathrm{~h}$, and dried in vacuum at $120{ }^{\circ} \mathrm{C}$ for 24 hours to afford polyimides P1-P5.<smiles>O=C1OC(=O)c2cc(OC3COC4COCC43)ccc21</smiles>

(5)

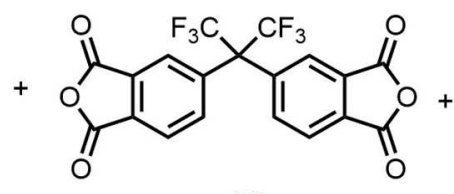

(6)<smiles>Nc1ccc(C2(c3ccccc3)c3ccccc3-c3ccccc32)cc1</smiles>

(7)

$X$

$100-X$ $3 \mathrm{~h}$
$180-200^{\circ} \mathrm{C}$

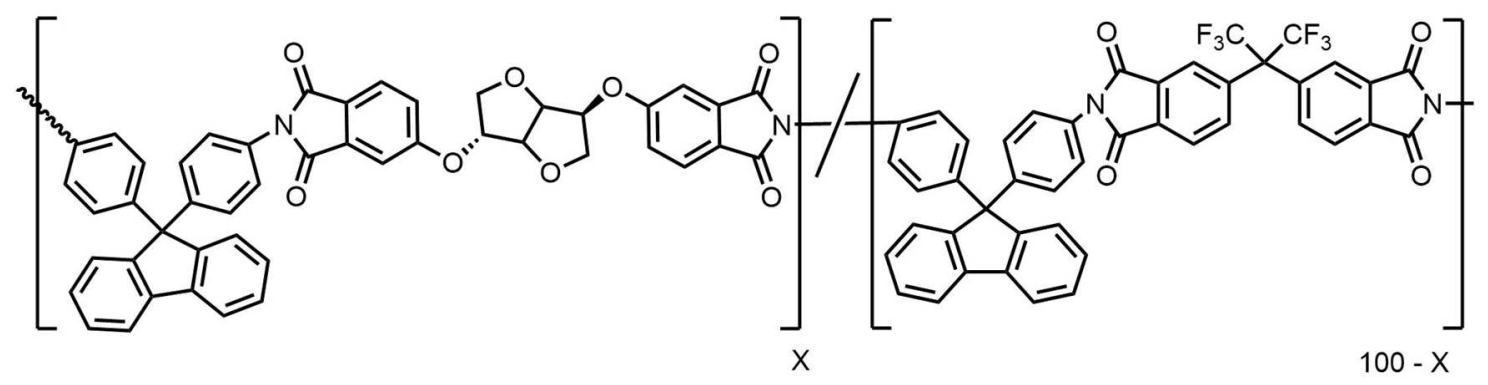

Figure 2: The synthetic routes of the homopolyimides and copolyimides P1-P5 (X=100, P1/ $\mathrm{X}=75, \mathrm{P} 2 / \mathrm{X}=50, \mathrm{P} 3 / \mathrm{X}=25, \mathrm{P} 4 / \mathrm{X}=0, \mathrm{P} 5)$

\subsection{Characterization Methods}

NMR spectra were obtained on a Brucker Advance 300 spectrometer (Brucker, Palaiseau, France), with frequencies of 300.1 and $75.5 \mathrm{MHz}$ respectively for ${ }^{1} \mathrm{H}$ and ${ }^{13} \mathrm{C}$ analysis. The solvent used was DMSO- $d 6$ and tetramethylsilane (TMS) was used as internal reference. 
Thermogravimetric analyses (TGA) were performed under nitrogen atmosphere at a heating rate of $10^{\circ} \mathrm{C} / \mathrm{min}$ from $25{ }^{\circ} \mathrm{C}$ to $500{ }^{\circ} \mathrm{C}$, using a TA Q50 Instrument (TA Instruments Division de Waters SAS, Guyancourt, France).

Tg were determined by thermomechanical analyses (TMA), with a TA Instruments modelQ400, under nitrogen, at a heating rate of $10^{\circ} \mathrm{C} / \mathrm{min}$ and in the penetration mode.

Molecular weights were determined by Size Exclusion chromatography (SEC) on a system equipped with a ShimadzuLC-20AD pump and a differential refractive index detector. $\mathrm{CDCl}_{3}$ was used as eluent. SEC analyses were achieved with Waters Styragel columns (HR2+HR1+HR0.5). Reported values (number average molar masses (Mn), weight average molar masses $(\mathrm{Mw})$ and chain disparities $(\mathrm{PD})$ were determined from a polystyrene calibration curve.

\subsection{Preparation of Polymer-Modified Gold Electrodes and Impedimetric Measurements}

Gold substrates (300 nm of gold layer/ $30 \mathrm{~nm}$ of titanium layer/ $300 \mathrm{~nm} \mathrm{SiO} 2 /$ p-type Si/300 nm SiO2) were provided by the French RENATECH network (LAAS, CNRS Toulouse). The gold electrodes were $1.2 \mathrm{~cm} \times 1.2 \mathrm{~cm}$ square plates. The gold surface was rinsed with acetone for $15 \mathrm{~min}$, rinsed with ultrapure water then dried under nitrogen flow. Then it was alternately immersed for 2 mins freshly prepared hot piranha solution, rinsed with ultrapure water, and dried under nitrogen flow. After the surface treatment, $5 \mu \mathrm{L}$ of $1 \mathrm{w} / \mathrm{w} \%$ chloroform solution of P1, P2, P3, P4 or P5 polymer was dropped on the electrode surface and then dried under nitrogen flow. Drop-coating was chosen because spin-coating was not applicable, due to the volatility of chloroform.

Electrochemical measurements were performed in a $5 \mathrm{~cm}^{3}$ Pyrex glass electrochemical cell equipped with the polymer-modified gold electrode $\left(0.07 \mathrm{~cm}^{2}\right.$ active area, defined by an O-ring seal), as a working electrode, a platinum counter-electrode and a $\mathrm{Ag} / \mathrm{AgCl}$ reference electrode. All measurements were carried out at room temperature $\left(23 \pm 3^{\circ} \mathrm{C}\right)$. When the polymermodified gold electrode was in contact with the $0.1 \mathrm{M}$ potassium citrate solution $(\mathrm{pH} 4.0$ ) containing the metallic ions, the measurements were performed after 10 minutes of equilibration. Electrochemical Impedance Spectroscopy (EIS) measurements were operated using a potentiostat-galvanostat Voltalab 80 (Hach, Germany). In these experiments, an amplitude of $10 \mathrm{mV}$, with a frequency range of $100 \mathrm{mHz}$ to $100 \mathrm{kHz}$, was superimposed to a $\mathrm{dc}$ voltage. The value of the dc voltage was the free potential of the modified electrode in 0.1 $\mathrm{M}$ potassium citrate solution at $\mathrm{pH}$ 4.0. The real and imaginary impedances were computed and a Nyquist plot was drawn. The impedance values were fitted, using Zview software from 
Scribner Associates, to a standard Randles equivalent circuit consisting of a parallel combination of a constant phase element (CPE) and a Faradaic impedance $\mathrm{Zf}$ in series with the solution resistance (Rs). The faradic impedance is a series combination of polarization resistance $(\mathrm{Rp})$ and the Warburg impedance $(\mathrm{W})$.

Surface morphology was observed by scanning electron microscopy (SEM)(VEGA TESCAN SEM).

\section{Results and Discussion}

\subsection{Physicochemical Characterization of the Resulting Polymers P1-P5}

Thepartiallybio-based dianhydide monomer (5) was synthesized according to the route described in Figure 1 with high yield. This dianhydride derived from isohexidewas synthesized according to a literature procedure with further optimization.

The general procedure adopted comprised three steps: firstly the nucleophilic substitution between the commercially available isosorbide and dinitrophtalonitrile under the catalysis of sodium hydride, followed by hydrolysis with $\mathrm{KOH}$, and subsequent dehydration using acetic anhydride. The structure and the high purity of the synthesized intermediate and monomer((3), (4) and (5))were confirmed by ${ }^{1} \mathrm{H}$ NMR analysis (representative NMR data presented in Figure S1).

Series of copolyimides were prepared from the synthesised bio-based dianhydride(5), the petrobased dianhydride (6) and the diamine (7) via one step polycondensation method in mcresol at $180{ }^{\circ} \mathrm{C}$ which last 3 hours, as illustrated in Figure 2.

A set of five experiments with different feed ratios ((5) / (6)) were conducted each time (100/0, $\mathrm{P} 1 ; 75 / 25$, P2; 50/50, P3; 25/75, P4; 0/100, P5;). The resulting polymers were isolated by precipitation in methanol and were purified by extraction with methanol in a Soxhlet extractor, followed by drying in a vacuum during $24 \mathrm{~h}$ at $120{ }^{\circ} \mathrm{C}$.

As shown in Table 1, the five synthesized polymers were obtained with good yields in the range of $72-99 \%$. All the resulting homopolyimides and copolyimides showed satisfactory molecular weight, indicated by their high number average molecular weight $(\mathrm{Mn})$. These values comprised in the $17600-22000 \mathrm{~g} / \mathrm{mol}$ range and with dispersity index (PD) between 4.03 and 4.79. For a given dianhydride, there was no significant difference in molecular weight values between (5) and(6) based polymers $(\mathrm{Mn}(\mathrm{P} 1)=\mathrm{Mn}(\mathrm{P} 2)=22000 \mathrm{~g} / \mathrm{mol})$. For the synthesized copolymers, 
the GPC results indicated a slight decrease in the molecular weight of the copolyimides compared to the homopolyimides which is probably due to the stoichiometry and the difference in reactivity of the monomers introduced.

Table 1. Yields, compositions, molecular weights and thermal behaviors of resulting polymers P1-P5.

\begin{tabular}{|c|c|c|c|c|c|c|c|c|c|c|}
\hline \multirow[t]{2}{*}{ Ref.Polymer } & \multirow[t]{2}{*}{$\begin{array}{c}\text { Yield }^{a)} \\
(\%)\end{array}$} & \multicolumn{2}{|c|}{$\begin{array}{c}\text { Composition } \\
\text { (5) / (6) }\end{array}$} & \multicolumn{3}{|c|}{ Molecular weight } & \multirow{2}{*}{\multicolumn{3}{|c|}{$\begin{array}{l}\mathbf{T g}^{\mathrm{e})} \\
\left({ }^{\circ} \mathbf{C}\right)\end{array}$}} & \multirow[t]{2}{*}{$\begin{array}{c}\left.\text { Td }{ }_{5 \%}{ }^{\mathrm{f}}\right) \\
\left({ }^{\circ} \mathbf{C}\right)\end{array}$} \\
\hline & & Feed $^{\text {b) }}$ & polymer ${ }^{\mathrm{c})}$ & $\mathbf{M}_{\mathbf{n}}^{\mathbf{d})}$ & $\mathbf{M}_{\mathbf{w}}^{\mathbf{d})}$ & $\mathbf{P D}^{\mathrm{d})}$ & & & & \\
\hline $\mathrm{P} 1$ & 99 & $100 / 0$ & $100 / 0$ & 22000 & 97000 & 4.36 & 318 & - & - & 451 \\
\hline $\mathrm{P} 2$ & 72 & $75 / 25$ & $78 / 22$ & 17600 & 70000 & 4.03 & 197 & 350 & 380 & 456 \\
\hline P3 & 88 & $50 / 50$ & $55 / 45$ & 20000 & 97000 & 4.79 & 414 & - & - & 462 \\
\hline $\mathrm{P} 4$ & 78 & $25 / 75$ & $26 / 74$ & 18000 & 73800 & 4.10 & 194 & 329 & 373 & 493 \\
\hline P5 & 98 & $0 / 100$ & $0 / 100$ & 22000 & 110000 & 4.92 & 387 & - & - & $>500$ \\
\hline
\end{tabular}

a)After precipitation into water and washing with methanol, evaporation under a vacuum at $120{ }^{\circ} \mathrm{C}$.

b)Molar ratio in the initial feed.c)Molar ratio in the copolyimides determined by ${ }^{1} \mathrm{H}$ NMR.

d)Number and weight-average $\left(\mathrm{M}_{\mathrm{n}}, \mathrm{M}_{\mathrm{w}}\right.$; in Da) molecular weights and polydispersity (PD) determined by GPC in $\mathrm{CDCl}_{3}$ against polystyrene standards.

e)Determined by thermomechanical analysis TMA, under nitrogen, at a heating rate of $10^{\circ} \mathrm{C} / \mathrm{min}$ and in the penetration mode.

f) $\mathrm{T}_{\mathrm{d} 5 \%}$ : temperature of $5 \%$ weight, determined by TGA, at a heating rate of $10^{\circ} \mathrm{C} \cdot \mathrm{min}^{-1}$, with a nitrogen flow rate at $50 \mathrm{~mL} / \mathrm{min}$.

The chemical structures of the prepared polyimides were confirmed by ${ }^{1} \mathrm{H}$ NMR and ${ }^{13} \mathrm{C}$ NMR and the results were in good agreement with the proposed structures. A detailed description of the NMR data recorded from homopolyimides and copolyimides are given in Figure S1.

As can be seen in the NMR spectra, the successful incorporation of isosorbide units into the polyimide chain were confirmed to be relatively quantitative by the group signals in the NMR spectra at 3.9-5.4 ppm (A detailed description are given in Figure S1). The resonance signals in the range of 7.81-8.11ppm were assigned to the aromatic protons of (6), protons of (7) as well as the aromatic protons from the monomer unit (5). The absence of end-groups on the NMR spectra clearly shows that these polyimides have a good molecular weight.

The incorporation of the monomers were observed to be relatively quantitative, confirming values of the molar ratio units in copolymers determined from integrated intensities of NMR signals of respective protons

The ${ }^{1} \mathrm{H}$ NMR spectroscopy technique was also helpful to calculate the actual molar composition of monomers compared to the initial feed ratios. The molar composition, presented in Table 1, state the proportion of (5) and (6) monomers in the copolyimides structure. The calculation of 
the ratios is founded on the integration of experimental NMR proton signals characterizing each of the two monomers that gives indication about the structural composition.

Results of these characterization methods were collected in Table 1. These calculated values based on ${ }^{1} \mathrm{H}$ NMR analysis agreed with the introduced feed ratios. The molar ratio in the copolyimides determined by ${ }^{1} \mathrm{H}$ NMR. values indicate a very slight difference compared to those of the molar ratio in the initial feed, in favor of the repeating unit of isosorbide. This can be explained by the higher reactivity of isosorbide compared to 6-FDA.

The study of the thermal behavior of the synthesized polyimides enlarges their potential application feed. The thermal properties of the polymers were investigated by thermogravimetric analyses (TGA) and thermomechanical analysis (TMA).

The glass transition temperatures of polyimides were carried outvia thermomechanical analysis (TMA) and the results are listed in Table 1. Homopolymers revealed a single glass transition displayed at $318{ }^{\circ} \mathrm{C}$ and at $387^{\circ} \mathrm{C}$. The homopolymer based on 6-FDA presents a higher temperature which is due to its structure more rigid ${ }^{48}$. In contrast to homopolymers the phase transition of copolymers is very broad. Indeed, the copolymers with disproportionate stoichiometry revealthree $\mathrm{Tg}$ which correspond to the $\mathrm{Tg}$ of each homopolymers and $\mathrm{Tg}$ corresponding to the miscible phase. Whereas, in the case of the copolymer P3 (feed ratios of $(5)=(6)=50 \%)$ a single $\mathrm{Tg}$ was observed, and their value is higher than of their corresponding parent homopolymers P1 and P5. When the stoichiometry is equivalent, the copolymer presents a single $\mathrm{Tg}$ greater than that of the homopolymers, When (5) and (6) are stoichiometrically equivalent $($ Ratio=1), the copolymer presents a single Tg greater than that of the homopolymers which can probably be explained by a better interaction between the molecular chains for the homopolymers.

The thermal stability of the obtained polyimides was assessed using thermogravimetric analyses (TGA), and the temperatures of $5 \%$ weight loss $\left(\mathrm{T}_{\mathrm{d} 5} \%\right)$ of these polymers are listed in Table 1 and thermograms in Figure S2. As observed in Table 1, the homopolyimide based on partially bio-based anhydride (5) shows rather lower stability $\left(\mathrm{T}_{\mathrm{d} 5 \%}=451{ }^{\circ} \mathrm{C}\right)$. Furthermore, we observed that thermal stability decreases as the portion of ISDA (isosorbide moieties (5)) increased. Despite this, all the synthesized polyimides are highly thermostable, with a starting decomposition temperature between $451-500^{\circ} \mathrm{C}$ (for homopolyimides based on 6FDA, $\mathrm{T}_{\mathrm{d} 5 \%}>500{ }^{\circ} \mathrm{C}$ ), which indicated that the incorporation of bio-based isosorbide moieties into homopolyimide or copolyimidebackbones was not noticeably detrimental to the thermal stability of the resulting polyimides. 
3.2. Study of the polyimide/electrolyte interface in presence of WFD heavy metal ions by EIS Measurements

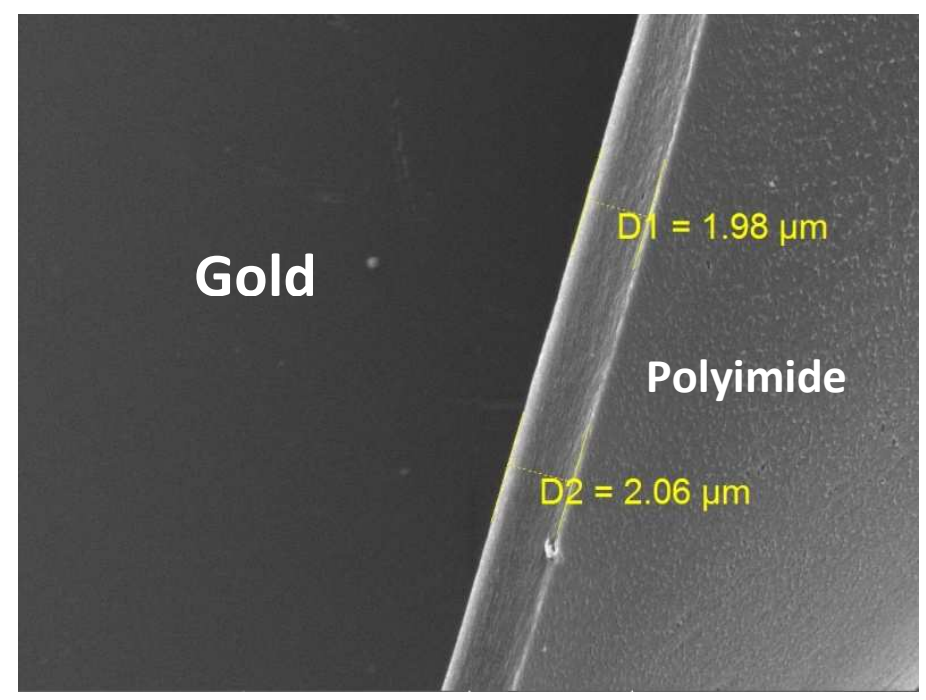

Figure 3. SEM image of a polyimide film deposited on gold surface.

The thickness a polyimide films on gold surface was determined by SEM (Figure 3). The average thickness of the polyimide films is $2.0 \pm 0.2 \mu \mathrm{m}$.

Nyquist diagrams of the gold electrode/polyimide/electrolyte obtained in presence of $\mathrm{Pb}^{2+}$ ion are presented in Figures 4 (a,b,c,d,e).

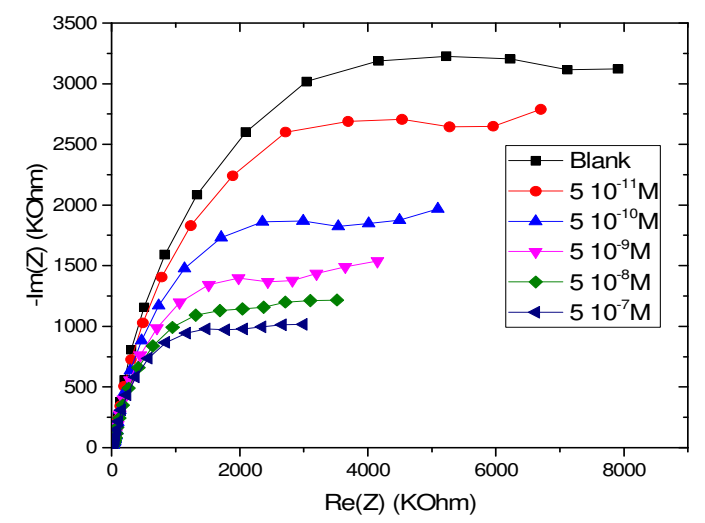

(a)

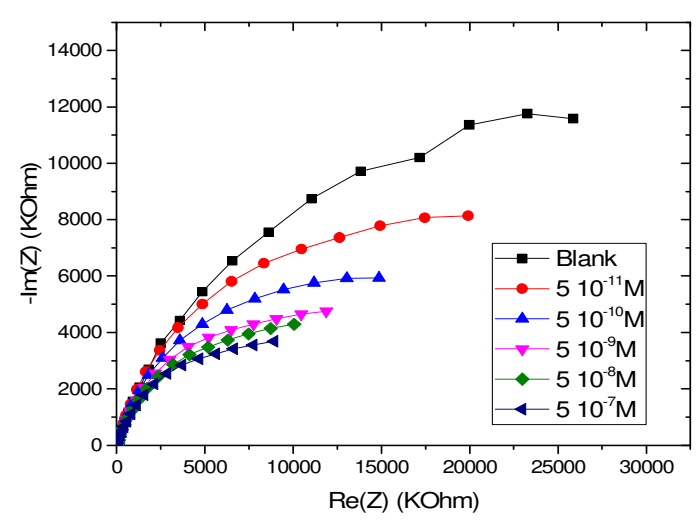

(b) 


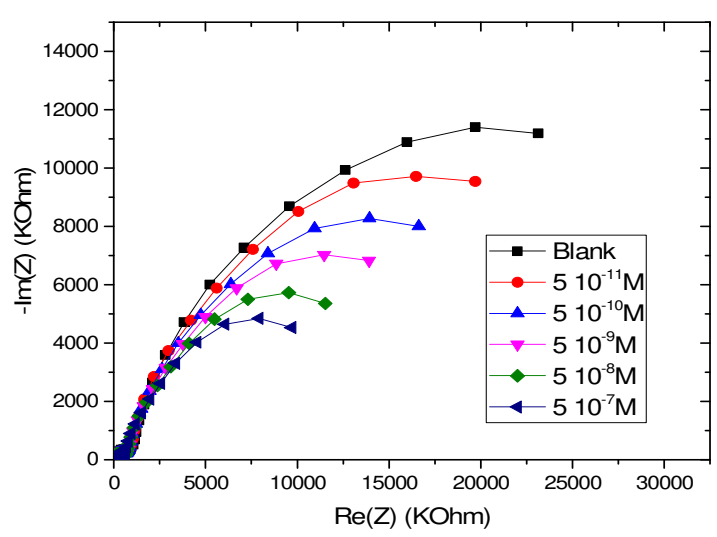

(c)

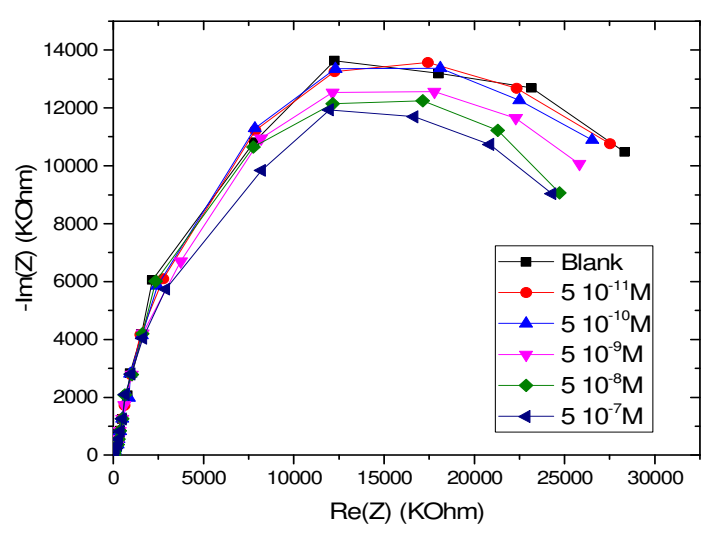

(d)

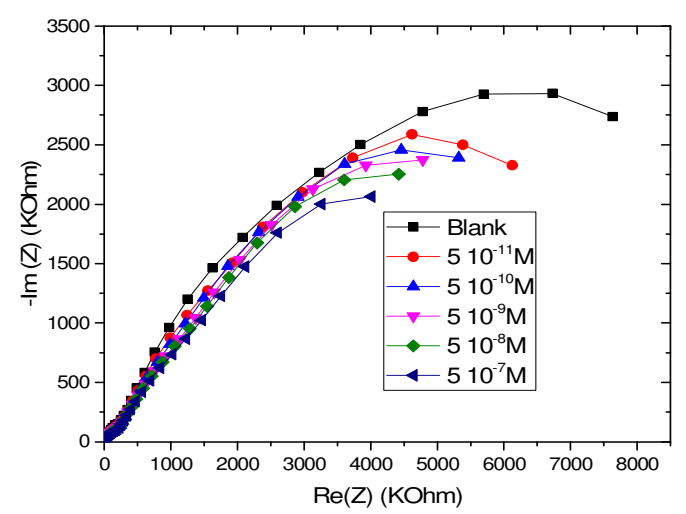

(e)

Figure 4. Nyquist plots of the gold electrode/polyimide/electrolyte obtained in presence of $\mathrm{Pb}^{2+}$ ion. Measuring solution: $0.1 \mathrm{M}$ potassium citrate solution at $\mathrm{pH} 4.0$

From the values of the imaginary part of the impedances of the homopolyimides (lower than $3500 \mathrm{kOhms}$ ) are lower than those of the copolyimides (in the range of $10^{4} \mathrm{kOhms}$ ). From this observation, it comes that the capacitance of the homopolyimides are higher, which is due to their higher dielectric constant. This point reflects their higher density due to a better interaction between the molecular chains for the homopolymers.

The main parameter of the standard Randles equivalent circuit affected when the concentration of $\mathrm{Pb}^{2+}$ increases, is the polarization resistance, as shown in Table 2. 
Table 2. Variation of the polarization resistance in the Randles standard equivalent circuit when the concentration of $\mathrm{Pb} 2+$ increases

\begin{tabular}{|c|c|c|c|c|c|}
\hline$[\mathrm{Pb}]$ & $\begin{array}{c}\mathrm{P} 1 \\
(\mathrm{Rp}(\mathrm{Ohm}))\end{array}$ & $\begin{array}{c}\mathrm{P} 2 \\
(\mathrm{Rp}(\mathrm{Ohm}))\end{array}$ & $\begin{array}{c}\mathrm{P} 3 \\
(\mathrm{Rp}(\mathrm{Ohm}))\end{array}$ & $\begin{array}{c}\mathrm{P} 4 \\
(\mathrm{Rp}(\mathrm{Ohm}))\end{array}$ & $\begin{array}{c}\mathrm{P} 5 \\
(\mathrm{Rp}(\mathrm{Ohm}))\end{array}$ \\
\hline Blank & $1.467610^{7}$ & $3.096110^{6}$ & $3.522110^{7}$ & $3.872710^{7}$ & $9.923310^{6}$ \\
$510^{-11} \mathrm{M}$ & $1.236010^{7}$ & $2.114910^{6}$ & $2.965610^{7}$ & $3.823010^{7}$ & $9.895510^{6}$ \\
$510^{-10} \mathrm{M}$ & $8.420310^{6}$ & $1.828910^{6}$ & $2.558810^{7}$ & $3.748510^{7}$ & $9.441510^{6}$ \\
$510^{-9} \mathrm{M}$ & $6.445310^{6}$ & $1.497410^{6}$ & $2.221310^{7}$ & $3.528310^{7}$ & $8.418910^{6}$ \\
$510^{-8} \mathrm{M}$ & $5.400710^{6}$ & $1.366910^{6}$ & $1.755810^{7}$ & $3.391010^{7}$ & $7.980010^{6}$ \\
$510^{-7} \mathrm{M}$ & $4.770110^{6}$ & $1.121110^{6}$ & $1.485110^{7}$ & $3.242510^{7}$ & $6.909010^{6}$ \\
\hline
\end{tabular}

The relative variation of the polarization resistance is proportional to the adsorbed concentration $\mathrm{q}_{\mathrm{e}}$ of $\mathrm{Pb}^{2+}$ at the polyimide surface. The adsorption isotherm of $\mathrm{Pb}^{2+}$ was then built from this value. The initial concentration of $\mathrm{Pb}^{2+}$ was not highly modified, due to the small surface area of the polymer in contact. Two models were tested: Langmuir and Freundlich. The Langmuir model assumes that adsorption occurs on a structurally homogeneous adsorbent in a monolayer, or that the adsorption occurs at fixed sites that are identical and energetically equivalent. The linearized form of the Langmuir isotherm can be written as follows:

$c_{e} / q_{e}=1 / Q_{0} b+c_{e} / Q_{0}$

where $c_{e}$ is the concentration in solution and $\mathrm{q}_{\mathrm{e}}$, the adsorbed concentration, $\mathrm{Q}_{0}$ is the adsorption capacity and $\mathrm{b}$ is the energy of adsorption $\left(\mathrm{M}^{-1}\right)$. Due to our assessment of $\mathrm{q}_{\mathrm{e}}$, the obtained value of $\mathrm{Q}_{0}$ is a relative value.

Freundlich isotherm is another form of the Langmuir model describing a heterogeneous system with multiple adsorption sites. The linearized logarithmic form of the Freundlich model can be expressed as follows:

$\log q_{e}=\log K_{F}+(1 / n) \log c_{e}$

where $\mathrm{K}_{\mathrm{F}}$ is the relative value of the Freundlich constant and $\mathrm{n}$ is the Freundlich exponent. 
The modelling parameters are given in Tables $3 \mathrm{a}$ and $3 \mathrm{~b}$.

Table 3a. Parameters of Langmuir model of $\mathrm{Pb}^{2+}$ adsorption isotherms on the different polyimides.

\begin{tabular}{|l|l|l|l|}
\hline Polymer & $\mathrm{R}^{2}$ & $\mathrm{Q}_{0}$ & $\mathrm{~b}\left(\mathrm{M}^{-1}\right)$ \\
\hline P1 & 0.9998 & 0.726 & $2.177 \times 10^{-9}$ \\
\hline P2 & 0.9999 & 0.641 & $1.281 \times 10^{-9}$ \\
\hline P3 & 0.9997 & 0.605 & $2.418 \times 10^{-9}$ \\
\hline P4 & 0.9992 & 0.165 & $4.942 \times 10^{-9}$ \\
\hline P5 & 0.9992 & 0.262 & $7.847 \times 10^{-9}$ \\
\hline
\end{tabular}

Table 3b. Parameters of Freundlich model of $\mathrm{Pb}^{2+}$ adsorption isotherm on the different polyimides.

\begin{tabular}{|l|l|l|l|}
\hline Polymer & $\mathrm{R}^{2}$ & $1 / \mathrm{n}$ & $\mathrm{K}_{\mathrm{F}}$ \\
\hline P1 & 0.959 & 0.096 & 3.120 \\
\hline P2 & 0.945 & 0.079 & 2.156 \\
\hline P3 & 0.978 & 0.063 & 1.513 \\
\hline P4 & 0.925 & 0.308 & 19.957 \\
\hline P5 & 0.874 & 0.422 & 200.955 \\
\hline
\end{tabular}

Considering the $\mathrm{R}^{2}$ value, the Langmuir model fits perfectly $\mathrm{Pb}^{2+}$ adsorption isotherm. The higher value of $\mathrm{Q}_{0}$ is obtained with polymer P1.Value of $1 / \mathrm{n}$ for all the polymers being less than 1 , it means that the adsorption process is favorable for all the polymers. The adsorption on polyimides containing isosorbid moieties (5) is more favorable for $\mathrm{Pb}^{2+}$ adsorption. This property could be due to the hydrophilicity of these moieties.

The adsorption isotherms of all the WFD heavy metals on polymer P1were fitted according to the Langmuir and Freundlich models (Tables $4 \mathrm{a}$ and $4 \mathrm{~b}$ ).

Table 4a. Parameters of the Langmuir model of WFD heavy metals on polymer P1.

\begin{tabular}{|l|l|l|l|}
\hline Heavy metal ion & $\mathrm{R}^{2}$ & $\mathrm{Q}_{0}$ & $\mathrm{~b}(\mathrm{~L} / \mathrm{mg})$ \\
\hline $\mathrm{Pb}$ & 0.9998 & 0.726 & $2.177 \times 10^{-9}$ \\
\hline $\mathrm{Ni}$ & 0.9999 & 0.818 & $1.636 \times 10^{-9}$ \\
\hline $\mathrm{Cd}$ & 0.9998 & 0.488 & $2.444 \times 10^{-9}$ \\
\hline $\mathrm{Hg}$ & 0.9998 & 0.084 & $2.506 \times 10^{-9}$ \\
\hline
\end{tabular}

Table 4b. Parameters of the Freundlich model of WFD heavy metals on polymer P1.

\begin{tabular}{|l|l|l|l|}
\hline Heavy metal ion & $\mathrm{R}^{2}$ & $1 / \mathrm{n}$ & $\mathrm{K}_{\mathrm{F}}$ \\
\hline $\mathrm{Pb}$ & 0.959 & 0.096 & 3.120 \\
\hline $\mathrm{Ni}$ & 0.969 & 0.064 & 2.157 \\
\hline
\end{tabular}




\begin{tabular}{|l|l|l|l|}
\hline $\mathrm{Cd}$ & 0.963 & 0.102 & 2.301 \\
\hline $\mathrm{Hg}$ & 0.908 & 0.181 & 1.420 \\
\hline
\end{tabular}

For all the WFD heavy metals, the Langmuir model gives the best fitting. The higher value of Q 0 is obtained for $\mathrm{Ni}^{2+}$ and $\mathrm{Pb}^{2+}$. According to $1 / \mathrm{n}$ values, adsorption of $\mathrm{Ni}^{2+}$ and $\mathrm{of}^{2+}$ are more favorable. The adsorption of $\mathrm{Hg}^{2+}$ is the less favorable. These results are within the paradigm of Pearson's HSAB principle, wherein borderline cations $\mathrm{Pb}^{2+}$ and $\mathrm{Ni}^{2+}$ are expected to interact more strongly with the hard anion (O-) and, consequently, soft cations $\left(\mathrm{Cd}^{2+}\right.$ and $\mathrm{Hg}^{2+}$ ) interact the least ${ }^{49}$. A complex configuration is proposed in Figure 5, as a similar conformation as that proposed for xanthone-based polyimides ${ }^{42}$.

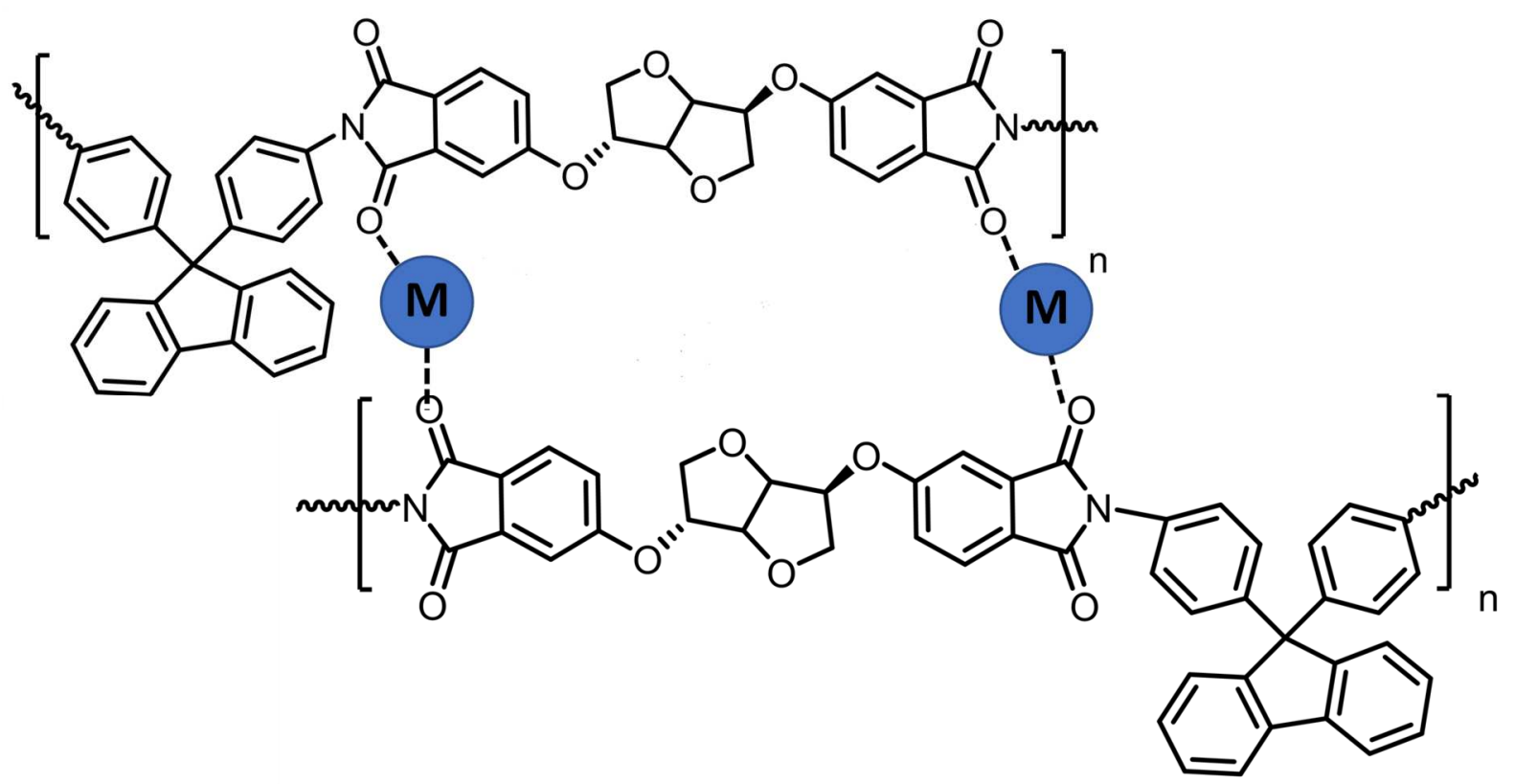

Figure 5. Metal-polyimide complex based on oxygen-heavy metal interaction.

The relative variation of the polarization resistance $(\Delta R / R)$ is the response of the P1 modified gold electrode for the detection of WFD heavy metal ions. The sensitivity of detection (S) is defined as the slope of the straight line of $\Delta R / R$ versus log of metal concentration. The analytical performance of this heavy metal sensor is presented in Table 5, LOD being the Limit of Detection, determined as $3 \sigma / \mathrm{S}$, $\sigma$ being the background of the blank.

Table 5. Analytical performance of the isosorbide based polyimide (P1) modified gold electrode with impedance measurements (Sensitivity, detection limit, linear range) compared to those obtained with anodic stripping voltammetry (ASV) on a boron-doped diamond electrode (BDD) and those of a potentiometric sensor. 


\begin{tabular}{|l|l|l|l|l|}
\hline Heavy Metal Ion & $\begin{array}{l}\text { Electrochemical } \\
\text { Methods }\end{array}$ & Sensitivity & LOD $[\mathrm{M}]$ & Linear range $[\mathrm{M}]$ \\
\hline \multirow{3}{*}{$\mathrm{Pb}^{2+}$} & Impedancemetry & $0.111 /$ decade & $5 \times 10^{-11}$ & $5 \times 10^{-11}-5 \times 10^{-7}$ \\
\cline { 2 - 5 } & ASV & $0.069 \mathrm{nA} / \mathrm{nM}$ & $5.5 \times 10^{-9}$ & $5.5 \times 10^{-9}-48 \times 10^{-9}$ \\
\cline { 2 - 5 } & Potentiometry & $29.7 \mathrm{mV} /$ decade & $4 \times 10^{-9}$ & $1 \times 10^{-8}-1 \times 10^{-4}$ \\
\hline \multirow{2}{*}{$\mathrm{Ni}^{2+}$} & Impedancemetry & $0.087 /$ decade & $5 \times 10^{-11}$ & $5 \times 10^{-11}-5 \times 10^{-7}$ \\
\cline { 2 - 5 } & ASV & $0.024 \mathrm{nA} / \mathrm{mM}$ & $6.8 \times 10^{-9}$ & $6.8 \times 10^{-9}-97 \times 10^{-9}$ \\
\hline $\mathrm{Cd}^{2+}$ & Impedancemetry & $0.073 /$ decade & $5 \times 10^{-11}$ & $5 \times 10^{-11}-5 \times 10^{-7}$ \\
\cline { 2 - 5 } & ASV & $0.015 \mathrm{nA} / \mathrm{nM}$ & $0.4 \times 10^{-9}$ & $0.4 \times 10^{-9}-35 \times 10^{-9}$ \\
\hline \multirow{2}{*}{$\mathrm{Hg}^{2+}$} & Impedancemetry & $0.018 /$ decade & $5 \times 10^{-11}$ & $5 \times 10^{-11}-5 \times 10^{-7}$ \\
\cline { 2 - 5 } & ASV & $0.012 \mathrm{nA} / \mathrm{nM}$ & $2.3 \times 10^{-9}$ & $2.3 \times 10^{-9}-5 \times 10^{-9}$ \\
\hline
\end{tabular}

For $\mathrm{P} 1$, with impedance measurements, the higher sensitivity is obtained for $\mathrm{Pb}^{2+}$ and the lower for $\mathrm{Hg}^{2+}$. The detection limit obtained with P1 for is $50 \mathrm{pM}$ for all the WFD heavy metals. This detection limit of $\mathrm{Pb}^{2+}$ is 110 times lower than that obtained by anodic stripping voltammetry on boron-doped diamond electrode (BDD), $5.5 \mathrm{nM} \mathrm{[50]} \mathrm{and} \mathrm{that} \mathrm{obtained} \mathrm{by} \mathrm{potentiometry,} 4$ $\mathrm{nM}$ [51]. Its dynamic range is four decades which is larger than that obtained with ASV (one decade) and equal to that of potentiometry (four decades). Comparing the detection limit of the other WFD heavy metals obtained with ASV to those obtained with P1 and impedance measurements, it is 136 times higher for $\mathrm{Ni}^{2+}, 8$ times higher for $\mathrm{Cd}^{2+}$ and 46 times higher for $\mathrm{Hg}^{2+}$.

\section{Conclusions}

The novelty of this work consists on the synthesis and characterization of new biosourced polyimides derived from unprecedented combinations of monomers (Isosorbide, 6-FDA and amine cardo), to introduce new properties. The characterization of the resulting polymers was obtained by NMR spectroscopy, SEC, TMA, TGA and AFM. All polymers have a high thermal stability with $5 \%$ weight loss above $451{ }^{\circ} \mathrm{C}$ in nitrogen atmosphere. Metal ion adsorption capacities of polymers were measured on the polyimide modified gold electrode interface by EIS. The obtained results showed that the incorporation of the dianhydride based on isosorbide (5) to the main chain enhance the adsorption capacity of lead ion. The equilibrium adsorption data of all polymers were found to adopt the Langmuir isotherm model. Regarding the adsorption capacities of the different WFD heavy metals on the isosorbide based homopolyimide (P1), the sequence was as follows: $\mathrm{Pb}^{2+} \approx \mathrm{Ni}^{2+}>\mathrm{Cd}^{2+}>\mathrm{Hg}^{2+}$. The developed bio-based polyimide modified sensor displayed a good sensitivity with a detection limit up to $50 \mathrm{pM}$ for all the WFD heavy metals which can prove its potential for the control of drinkable 
water contamination. Moreover, due to its affinity for WFD heavy metals, the isosorbide-based polyimide is a potential candidate for their removal from effluents.

Funding: We would like to acknowledge the Financial support of CAMPUS-FRANCE and Institut Français of the French Embassy in Tunisia (Dr. Pierre Durand De Ramefort) for the SSHN grant, of the High Ministry of Education and Research in Tunisia for doctoral grant and European Commission for TUNWIN project Grant \#952306.

\section{CRediT authorship contribution statement}

Ibtissem Jlalia: Investigation. Fares Zouaoui : Investigation. Taha Chabbah: Investigation.

Saber Chatti: Writing - original draft. Patrice Saint-Martin: Methodology. Herve Casabianca: Conceptualization. Sylvain Minot: Methodology. Francois Bessueille : Methodology. Catherine Marestin : Conceptualization. Regis Mercier: Conceptualization. Abdelhamid Errachid: Funding acquisition. Houyem Abderrazak: Writing - original draft. Mohamed Hammami: Funding acquisition. Nicole Jaffrezic-Renault: Writing - review \& editing.

\section{Declaration of Competing Interest}

The authors report no declarations of interest.

Data availability statement: The data that support the findings of this study are available from the corresponding author.

\section{REFERENCES}

${ }^{1} \mathrm{~F}$. Fenglian, W. Qi: Removal of heavy metal ions from wastewaters: A review, Journal of Environmental Management 92 (2011) 407-418https://doi.org/10.1016/j.jenvman.2010.11.011

${ }^{2}$ E. Bazrafshan, L. Mohammadi, A. Ansari-Moghaddam, A.H. Mahvi, Heavy metals removal from aqueous environments by electrocoagulation process - A systematic review, J. Environ. Heal. Sci. Eng. 13 (2015). https://doi.org/10.1186/s40201-015-0233-8

${ }^{3}$ A. Ahmed, Heavy metal pollution - A mini review, J. Bacteriol. Mycol. Open Access. 6 (2018) $179-181$. https://doi.org/10.15406/ibmoa.2018.06.00199.006

${ }^{4}$ A.T. Jan, M. Azam, K. Siddiqui, A. Ali, I. Choi, Q.M.R. Haq, Heavy metals and human health: Mechanistic insight into toxicity and counter defense system of antioxidants, Int. J. Mol. Sci. 16 (2015) 29592-29630. https://doi.org/10.3390/ijms161226183

${ }^{5}$ European Commission, EC, COMMISSION IMPLEMENTING DECISION (EU) 2018/840 of 5 June 2018, Off. J. Eur. Union. 141 (2018) 9-12 
${ }^{6}$ A. Dąbrowski, Z. Hubicki, P. Podkościelny, E. Robens, Selective removal of the heavy metal ions from waters and industrial wastewaters by ion-exchange method, Chemosphere. 56 (2004) 91-106. https://doi.org/10.1016/i.chemosphere.2004.03.006.

7. Esalah, M.M. Husein, Removal of heavy metals from aqueous solutions by precipitation-filtration using novel organo-phosphorus ligands, Sep. Sci. Technol. 43 (2008) 3461-3475. https://doi.org/10.1080/01496390802219661

${ }^{8}$ A.E. Burakov, E. V. Galunin, I. V. Burakova, A.E. Kucherova, S. Agarwal, A.G. Tkachev, V.K. Gupta, Adsorption of heavy metals on conventional and nanostructured materials for wastewater treatment purposes: A review, Ecotoxicol. Environ. Saf. 148 (2018) 702-712. https://doi.org/10.1016/i.ecoenv.2017.11.034.

${ }^{9}$ D.L. Oatley-Radcliffe, M. Walters, T.J. Ainscough, P.M. Williams, A.W. Mohammad, N. Hilal, Nanofiltration membranes and processes: A review of research trends over the past decade, Journal 648 of Water Process Engineering. 19 (2017) 164-171. https://doi.org/10.1016/i.jwpe.2017.07.026.

${ }^{10}$ T.K. Tran, H.J. Leu, K.F. Chiu, C.Y. Lin, Electrochemical Treatment of Heavy Metal-containing Wastewater with the Removal of COD and Heavy Metal Ions, J. Chinese Chem. Soc. 64 (2017) 493-502. https://doi.org/10.1002/iccs.201600266.

${ }^{11} \mathrm{~A}$. Waheed, M. Mansha, N. Ullah, Nanomaterials-based electrochemical detection of heavy metals in water: Current status, challenges and future direction, TrAC - Trends Anal. Chem. 105 (2018) 37-51. https://doi.org/10.1016/i.trac.2018.04.012.

${ }^{12}$ L. Eddaif, A. Shaban, J. Telegdi, Sensitive detection of heavy metals ions based on the calixarene derivativesmodified piezoelectric resonators: a review, Int. J. Environ. Anal. Chem. 99 (2019) 824-853. https://doi.org/10.1080/03067319.2019.1616708

${ }^{13}$ T. Gong, J. Liu, X. Liu, J. Liu, J. Xiang, Y. Wu, A sensitive and selective sensing platform based on CdTe QDs in the presence of L-cysteine for detection of silver, mercury and copper ions in water and various drinks, Food Chem. 213 (2016) 306-312. https://doi.org/10.1016/i.foodchem.2016.06.091.

${ }^{14}$ V.N. Losev, O. V. Buyko, A.K. Trofimchuk, O.N. Zuy, Silica sequentially modified with polyhexamethylene guanidine and Arsenazo I for preconcentration and ICP-OES determination of metals in natural waters, Microchem. J. 123 (2015) 84-89. https://doi.org/10.1016/i.microc.2015.05.022.

${ }^{15}$ R. Sitko, P. Janik, B. Zawisza, E. Talik, E. Margui, I. Queralt, Green Approach for Ultratrace Determination of Divalent Metal Ions and Arsenic Species Using Total-Reflection X-ray Fluorescence Spectrometry and MercaptoModified Graphene Oxide Nanosheets as a Novel Adsorbent, Anal. Chem. 87 (2015) 3535-3542. https://doi.org/10.1021/acs.analchem.5b00283.

${ }^{16}$ A.P.M. Michel, F. Sonnichsen, Laser induced breakdown spectroscopy for heavy metal detection in a sand matrix, Spectrochim. Acta - Part B At. Spectrosc. 125 (2016) 177-183. https://doi.org/10.1016/j.sab.2016.10.001. ${ }^{17} \mathrm{C}$. Sarzanini, M.C. Bruzzoniti, Metal species determination by ion chromatography, TrAC - Trends Anal. Chem. 20 (2001) 304-310. https://doi.org/10.1016/S0165-9936(01)00071-1.001.

${ }^{18}$ O.B.O. C, M.C. A, R.E. N, N.I. J, Simultaneous ultraviolet-visible (UVVIS) spectrophotometric quantitative determination of $\mathrm{Pb}, \mathrm{Hg}, \mathrm{Cd}$, As and $\mathrm{Ni}$ ions in aqueous solutions using cyanidin as a chromogenic reagent, Int. J. Phys. Sci. 8 (2013) 98-102. https://doi.org/10.5897/ijps12.670.

${ }^{19} \mathrm{~F}$. Zhao, Z. Chen, F. Zhang, R. Li, J. Zhou, Ultra-sensitive detection of heavy metal ions in tap water by laserinduced breakdown spectroscopy with the assistance of electrical-deposition, Anal. Methods. 2 (2010) 408-414. https://doi.org/10.1039/b9ay00160c

${ }^{20}$ R. Jain, S. Sharma, Glassy carbon electrode modified with multi-walled carbon nanotubes sensor for the quantification of antihistamine drug pheniramine in solubilized systems, J. Pharm. Anal. 2 (2012) 56-61. https://doi.org/10.1016/i.jpha.2011.09.013

${ }^{21}$ L. Pujol, D. Evrard, K. Groenen-Serrano, M. Freyssinier, A. Ruffien-Cizsak, P. Gros, Electrochemical sensors and devices for heavy metals assay in water: The French groups' contribution, Front. Chem. 2 (2014) 1-24. https://doi.org/10.3389/fchem.2014.00019.

${ }^{22} \mathrm{M}$. Miu, A. Angelescu, I. Kleps, M. Simion, Electrochemical sensors for heavy metals detection in liquid media. International Journal of Environmental Analytical Chemistry, 85 (2005) 9-11, 675679. https://doi:10.1080/03067310500146128

${ }^{23}$ A.J. Borrill, N.E. Reily, J. V. Macpherson, Addressing the practicalities of anodic stripping voltammetry for heavy metal detection: A tutorial review, Analyst. 144 (2019) 6834-6849. https://doi.org/10.1039/c9an01437c.03067310500146128

${ }^{24} Y$. Lu, X. Liang, C. Niyungeko, J. Zhou, J. Xu, G. Tian, A review of the identification and detection of heavy metal ions in the environment by voltammetry, Talanta. 178 (2018) 324-338. https://doi.org/10.1016/j.talanta.2017.08.033. 
${ }^{25}$ B.K. Bansod, T. Kumar, R. Thakur, S. Rana, I. Singh, A review on various electrochemical techniques for heavy metal ions detection with different sensing platforms, Biosens. Bioelectron. 94 (2017) 443-455. https://doi.org/10.1016/i.bios.2017.03.031

${ }^{26}$ W. Ben Mefteh, H. Touzi, Y. Chevalier, F. Bessueille, R. Kalfat, N.J. Renault, Gold electrodes functionalized by methyl-naphthyl substituted cyclam films for the detection of metal ions, Sensors Actuators, B Chem. 213 (2015) 334-342. https://doi.org/10.1016/j.snb.2015.02.109.031

${ }^{27} \mathrm{~L}$. Cui, J. Wu, H. Ju, Electrochemical sensing of heavy metal ions with inorganic, organic and bio-materials, Biosens. Bioelectron. 63 (2015) 276-286. https://doi.org/10.1016/j.bios.2014.07.052

${ }^{28}$ C. Wang ,R. Chu, Z. Guan,Z.Ullah, H. Song, Y. Zhang, C. Yu, L. Zhao,Q. Li, L. Liu .Tailored polyimide as positive electrode and polyimide-derived carbon as negative electrode for sodium ion full batteries. Nanoscale, 12 (2020) 47294735 https://doi.org/10.1039/C9NR09237D.

${ }^{29}$ M. Akhtar, A. Tahir, S. Zulfiqar, F. Hanif, M.F. Warsi, P.O. Agboola, I. Shakir, Ternary hybrid of polyanilinealanine-reduced graphene oxide for electrochemical sensing of heavy metal ions, Synth. Met. 265 (2020). https://doi.org/10.1016/i.synthmet.2020.116410.

${ }^{30}$ M. Lo, M. Seydou, A. Bensghaïer, R. Pires, D. Gningue-Sall, J.J. Aaron, Z. Mekhalif, J. Delhalle, M.M. Chehimi, Polypyrrole-wrapped carbon nanotube composite films coated on diazonium-modified flexible ITO sheets for the electroanalysis of heavy metal ions, Sensors (Switzerland). 20 (2020) 1-18. https://doi.org/10.3390/s20030580. ${ }^{31}$ E.K. Savan, S. Koytepe, A. Pasahan, G. Erdogdu, T. Seckin, Amperometric Simultaneous Measurement of Copper and Cobalt lons with Polythiophene Incorporating Pendant Terpyridine Groups, Polym. - Plast. Technol. Eng. 53 (2014) 1817-1824. https://doi.org/10.1080/03602559.2014.935405

${ }^{32}$ H. Sanaeepur, A. Ebadi Amooghin, S. Bandehali, A. Moghadassi, T. Matsuura, B. Van der Bruggen, Polyimides in membrane gas separation: Monomer's molecular design and structural engineering, Prog. Polym. Sci. 91 (2019) 80-125. https://doi.org/10.1016/i.progpolymsci.2019.02.001

${ }^{33}$ Y. Zhuang, J.G. Seong, Y.M. Lee, Polyimides containing aliphatic/alicyclic segments in the main chains, Prog. Polym. Sci. 92 (2019) 35-88. https://doi.org/10.1016/j.progpolymsci.2019.01.004.

34J. Boudaden, M. SteinmaßI, H.E. Endres, A. Drost, I. Eisele, C. Kutter, P. Müller-Buschbaum, Polyimide-based capacitive humidity sensor, Sensors $\quad$ (Switzerland). $18 \quad$ (2018) https://doi.org/10.3390/s18051516.01496390802219661.

${ }^{35}$ C.M. Nguyen, W.D. Huang, S. Rao, H. Cao, U. Tata, M. Chiao, J.C. Chiao, Sol-gel iridium oxide-based pH sensor array on flexible polyimide substrate, IEEE Sens. J. 13 (2013) 3857-3864. https://doi.org/10.1109/JSEN.2012.2236551

${ }^{36}$ Y.Y. Lv, J. Wu, Z.K. Xu, Colorimetric and fluorescent sensor constructing from the nanofibrous membrane of porphyrinated polyimide for the detection of hydrogen chloride gas, Sensors Actuators, B Chem. 148 (2010) 233239. https://doi.org/10.1016/i.snb.2010.05.029.

${ }^{37}$ C. Wu, B.-O. Guan, C. Lu, H.-Y. Tam, Salinity sensor based on polyimide-coated photonic crystal fiber, Opt. Express. 19 (2011) 20003. https://doi.org/10.1364/oe.19.020003.

${ }^{38}$ C. Zhang, S. Zhang, Y. Yan, F. Xia, A. Huang, Y. Xian, Highly Fluorescent Polyimide Covalent Organic Nanosheets as Sensing Probes for the Detection of 2,4,6-Trinitrophenol, ACS Appl. Mater. Interfaces. 9 (2017) 13415-13421. https://doi.org/10.1021/acsami.6b16423.

${ }^{39}$ Ö. Güngör, S. Köytepe, T. Seçkin, Polymer-Plastics Technology and Engineering Preparation of Novel Sensors Based on Polyimide Membrane for Sensitive and Selective Determination of Dopamine, (2015) 0-34. https://doi.org/10.1080/03602559.2015.1055503

${ }^{40}$ A. Alborzi, S. Zahmatkesh, A. Yazdanpanah, L-Lysine-derived optically active poly(hydrazide-imide)s: Synthesis, characterization and their application in removal of heavy metal ions, Polym. Bull. 70 (2013) 3359-3372. https://doi.org/10.1007/s00289-013-1027-8

${ }^{41}$ M.R. Vakili, S. Zahmatkesh, M.J. Panahiyan, T. Jafarizadeh, Poly(amide-hydrazide-imide)s containing L-aspartic acid: Synthesis, characterization, and their applications in removal of heavy metal ions, Des. Monomers Polym. 18 (2015) 315-322. https://doi.org/10.1080/15685551.2014.999463.

${ }^{42}$ A. Alborzi, S. Zahmatkesh, A. Yazdanpanah, L-Lysine-derived optically active poly(hydrazide-imide)s: Synthesis, characterization and their application in removal of heavy metal ions, Polym. Bull. 70 (2013) 3359-3372. https://doi.org/10.1007/s00289-013-1027-8

${ }^{43}$ F. Fenouillot, A. Rousseau, G. Colomines, R. Saint-Loup, J.P. Pascault, Polymers from renewable 1,4:3,6dianhydrohexitols (isosorbide, isomannide and isoidide): A review, Prog. Polym. Sci. 35 (2010) 578-622. https://doi.org/10.1016/i.progpolymsci.2009.10.001.8

${ }^{44}$ W. Qiu, L. Xu, C.C. Chen, D.R. Paul, W.J. Koros, Gas separation performance of 6FDA-based polyimides with different chemical structures, Polymer. 54 (2013) 6226-6235. https://doi.org/10.1016/j.polymer.2013.09.007.8 
${ }^{45} \mathrm{~S}$. Mehdipour-Ataei, H. Arabi, N. Bahri-Laleh, New soluble, thermally stable poly(amide-imide)s containing cardo anthraquinone unit, Eur. Polym. J. 42 (2006) 2343-2351. https://doi.org/10.1016/i.eurpolymi.2006.06.006.

${ }^{46}$ G.O. Yahaya, I. Mokhtari, A.A. Alghannam, S.H. Choi, H. Maab, A.A. Bahamdan, Cardo-type random copolyimide membranes for high pressure pure and mixed sour gas feed separations, J. Memb. Sci. 550 (2018) 526535. https://doi.org/10.1016/j.memsci.2017.10.063

${ }^{47}$ T. Chabbah, H. Abderrazak, R. Souissi, P. Saint-Martin, H. Casabianca, S. Chatti, R. Mercier, I. Rassas, A. Errachid, M. Hammami, N. Jaffrezic-Renault, A sensitive impedimetric sensor based on biosourced polyphosphine films for the detection of lead ions, Chemosensors. 8 (2020). https://doi.org/10.3390/CHEMOSENSORS8020034.

${ }^{48}$ Z. Mi, Z. Liu, J. Yao, C. Wang, C. Zhou, D. Wang, X. Zhao, H. Zhou, Y. Zhang, C. Chen, Transparent and soluble polyimide films from 1,4:3,6-dianhydro-D-mannitol based dianhydride and diamines containing aromatic and semiaromatic units: Preparation, characterization, thermal and mechanical properties, Polym. Degrad. Stab. 151 (2018) 80-89. https://doi.org/10.1016/i.polymdegradstab.2018.01.006.

${ }^{49}$ A. Bashir, T. Manzoor, L.A. Malik, A. Qureashi, A.H. Pandith, Enhanced and Selective Adsorption of Zn(II), Pb(II), $\mathrm{Cd}(\mathrm{II})$, and $\mathrm{Hg}(\mathrm{II})$ lons by a Dumbbell- And Flower-Shaped Potato Starch Phosphate Polymer: A Combined Experimental and DFT Calculation Study, ACS Omega. 5 (2020) 4853-4867. https://doi.org/10.1021/acsomega.9b03607.006

${ }^{50}$ A. Sbartai, P. Namour, A. Errachid, J. Krejci, R. Sejnohova, L. Renaud, M.L. Hamlaoui, A.S. Loir, F. Garrelie, C. Donnet, H. Soder, E. Audouard, J. Granier, N. Jaffrezic-Renault, Electrochemical Boron-Doped Diamond Film Microcells Micromachined with Femtosecond Laser: Application to the Determination of Water Framework Directive Metals, Anal. Chem. 84 (2012) 4805-4811. https://doi.org/10.1021/ac3003598

${ }^{51}$ M.R. Yaftian, M. Parinejad, D. Matt, A Lead-selective Membrane Electrode Based upon a Phosphorylated Hexahomotrioxacalix[3]arene, J. Chin. Chem. Soc. 54 (2007) 1535-1542.

https://doi.org/10.1002/iccs.200700216 